Prepared for the U.S. Department of Energy under Contract DE-AC05-76RL01830

\title{
Estimation of Equivalent Sea Level Cosmic Ray Exposure for Low Background Experiment
}

\author{
AT Greene \\ JL Orrell
}

August 2012

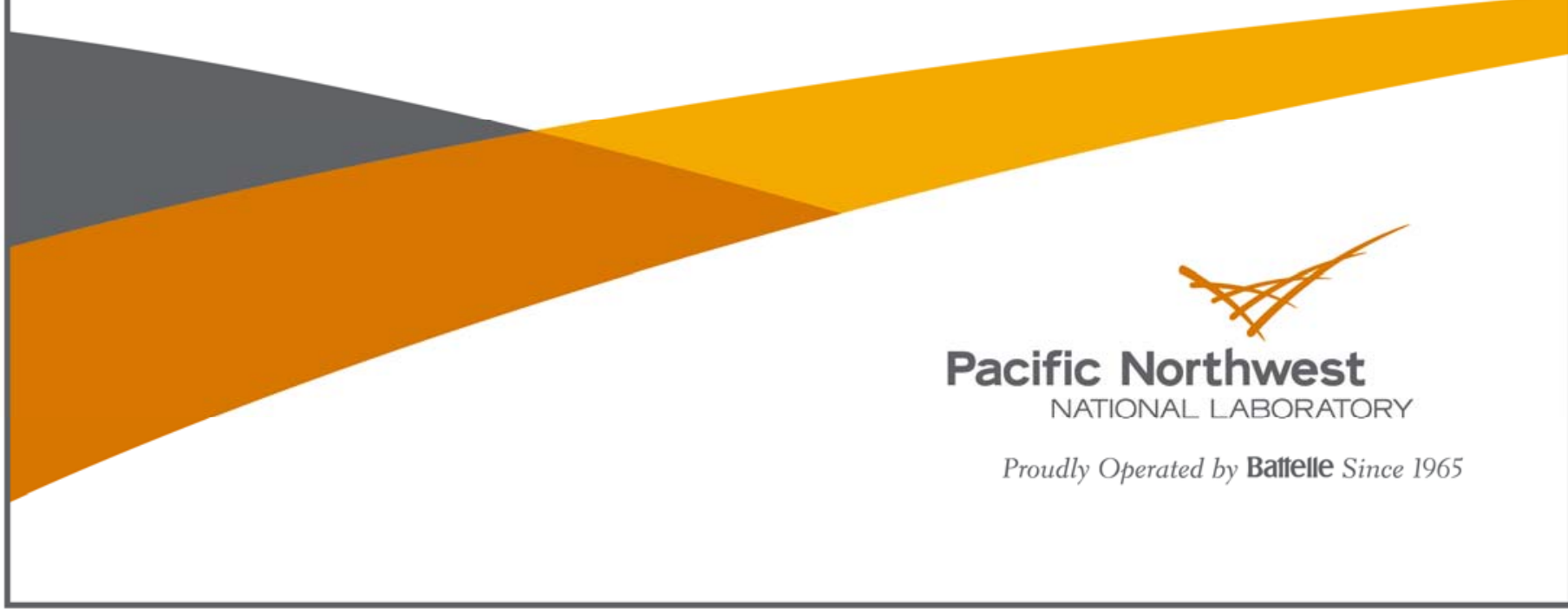




\title{
DISCLAIMER
}

This report was prepared as an account of work sponsored by an agency of the United States Government. Neither the United States Government nor any agency thereof, nor Battelle Memorial Institute, nor any of their employees, makes any warranty, express or implied, or assumes any legal liability or responsibility for the accuracy, completeness, or usefulness of any information, apparatus, product, or process disclosed, or represents that its use would not infringe privately owned rights. Reference herein to any specific commercial product, process, or service by trade name, trademark, manufacturer, or otherwise does not necessarily constitute or imply its endorsement, recommendation, or favoring by the United States Government or any agency thereof, or Battelle Memorial Institute. The views and opinions of authors expressed herein do not necessarily state or reflect those of the United States Government or any agency thereof.

\author{
PACIFIC NORTHWEST NATIONAL LABORATORY \\ operated by \\ BATTELLE \\ for the \\ UNITED STATES DEPARTMENT OF ENERGY \\ under Contract DE-AC05-76RL01830
}

Printed in the United States of America
Available to DOE and DOE contractors from the Office of Scientific and Technical Information, P.O. Box 62, Oak Ridge, TN 37831-0062; ph: (865) 576-8401 fax: $(865) 576-5728$
email: reports@adonis.osti.gov
Available to the public from the National Technical Information Service 5301 Shawnee Rd., Alexandria, VA 22312 ph: (800) 553-NTIS (6847) email: orders@ntis.gov $<$ http://www.ntis.gov/about/form.aspx> Online ordering: http://www.ntis.gov




\title{
Estimation of Equivalent Sea Level Cosmic Ray Exposure for Low Background Experiment
}

\author{
AT Greene \\ JL Orrell
}

August 2012

Prepared for

the U.S. Department of Energy

under Contract DE-AC05-76RL01830

Pacific Northwest National Laboratory

Richland, Washington 99352 



\section{Executive Summary}

While scientists at CERN and other particle accelerators around the world explore the boundaries of high energy physics, the Majorana project investigates the other end of the spectrum with its extremely sensitive, low background, low energy detector. The MAJORANA DEMONSTRATOR aims to detect neutrinoless double beta decay $(0 v \beta \beta)$, a rare theoretical process in which two neutrons decay into two protons and two electrons, without the emission of the two antineutrinos that are a product of a normal double beta decay. This process is only possible if - and therefore a detection would prove - the neutrino is a Majorana particle, meaning that it is its own antiparticle (Aaselth et al. 2004). The existence of such a decay would also disprove lepton conservation and give information about the neutrino's mass. 



\section{Acronyms and Abbreviations}

API

CERN

PNNL

SQL

SURF
Application programming interface

Conseil Européen pour la Recherche Nucléaire (French: European

Laboratory for Particle Physics; Geneva, Switzerland)

Pacific Northwest National Laboratory

Structured Query Language

Sanford Underground Research Facility 



\section{Contents}

Executive Summary .........................................................................................................................................ii

Acronyms and Abbreviations ......................................................................................................................

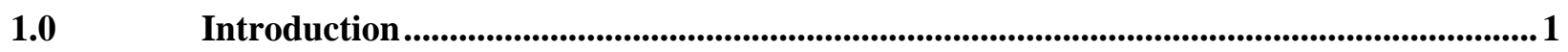

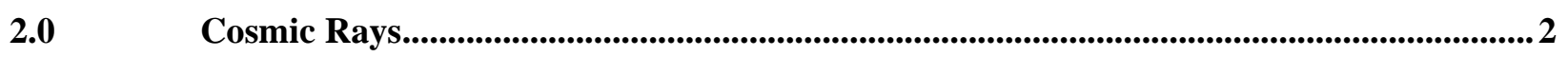

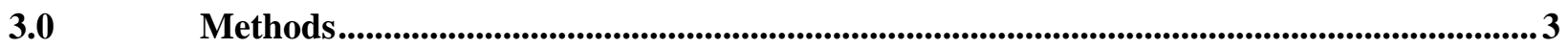

4.0 Results ..........................................................................................................................

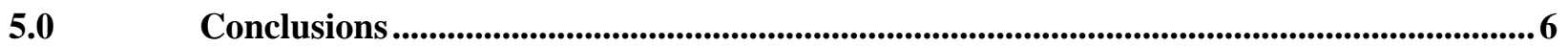

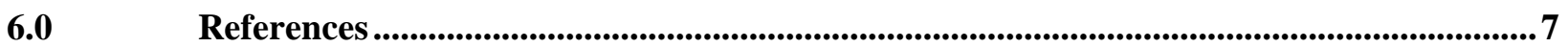





\subsection{Introduction}

While scientists at CERN and other particle accelerators around the world explore the boundaries of high energy physics, the Majorana project investigates the other end of the spectrum with its extremely sensitive, low background, low energy detector. The MAJORANA DEMONSTRATOR aims to detect neutrinoless double beta decay $(0 v \beta \beta)$, a rare theoretical process in which two neutrons decay into two protons and two electrons, without the emission of the two antineutrinos that are a product of a normal double beta decay. This process is only possible if - and therefore a detection would prove - the neutrino is a Majorana particle, meaning that it is its own antiparticle (Aaselth et al. 2004) . The existence of such a decay would also disprove lepton conservation and give information about the neutrino's mass.

Neutrinos, since they are electrically neutral and non-hadronic, interact only through gravity and the weak nuclear force, which are orders of magnitude weaker than electromagnetism and the strong nuclear force. This makes measuring neutrinos especially challenging, and is the primary reason — along with their tiny mass - that so much about neutrinos is still unknown. According to the Standard Model of particle physics, every particle has an antiparticle which is equal to it in mass, but opposite in charge; when a particle and its antiparticle come in contact they annihilate each other and produce energy. The positron (anti-electron) was first theorized by Dirac in 1931 and experimentally discovered in 1932 by Carl Anderson (1933). The neutrino is unique in its position as the only fundamental fermion with neutral charge, making it a potential Majorana candidate.

The history of neutrinos is closely tied to beta decay, as beta decay is actually the reason for the original postulation of their existence. Physicists observed that conservation laws required another particle to be produced which had yet to be detected, and it was correctly predicted that this particle must be extremely small and electrically neutral. Double beta decay, the process in which two neutrons decay simultaneously inside the same nucleus, is the rarest decay ever directly measured. The half-life for double beta decay in

${ }^{76}$ Germanium is on the order of $10^{21}$ years, which can be compared to the current estimated age of the Universe of $10^{10}$ years. Considering that it has not yet been detected, assuming it exists, $0 v \beta \beta$ must be an even rarer process. For this reason, large quantities of source material are required to have any chance of observing a significant number of decays within a reasonable time period for an experiment; the MAJORANA DEMONSTRATOR uses $40 \mathrm{~kg}$ of Germanium, with plans for a future ton-scale experiment. 


\subsection{Cosmic Rays}

One problem for the measurement is interference from background radiation, which could overwhelm the decay signal. A significant source of background radiation is cosmic rays, which are charged particles originating in outer space that cause a chain reaction particle cascade upon entering the atmosphere. To shield against cosmic-rays, the MAJORANA DEMONSTRATOR is located nearly a mile underground at the Sanford Underground Research Facility (SURF) in Lead, South Dakota. However cosmic rays also produce an indirect background through the activation products (such as ${ }^{60} \mathrm{Cobalt}$ ) they produce in the detector materials — ${ }^{63}$ Copper and ${ }^{76}$ Germanium (Laubenstein and Heusser 2009). These detector parts are built underground in various labs and universities, before being shipped to SURF and assembled together. An issue of concern is the number of activation products which will be produced during transport from the construction sites to SURF, and how this secondary source will affect the overall background.

To prevent excess background noise, the Majorana Collaboration has established a threshold for the maximum allowable radiation counts from cosmogenic sources. To verify that this limit is being adhered to, analysis was done using the known relation between altitude and cosmic ray flux to estimate the equivalent sea level exposure during transportation, and then from this infer the background contribution. 


\subsection{Methods}

CouchDB is an open source, free to use database framework that does not follow the more common structured query language (SQL) standards (Apache 2012). This gives a CouchDB database more freedom to store different kinds of records together in one database; as an example, the Majorana Parts Database contains both records for the detector parts themselves, and transportation records which track the movements of the parts. These transportation records were the main focus of analysis, so that the above ground exposure of the copper parts could be estimated.

In order to pull records out of the database and make it useful as input to software, it was necessary to interface with a programming language; the couchDB4j library for the Java language was chosen for this purpose. A tool was designed which could, using the transport records destination/origin locations and the start/end times, estimate the equivalent sea level exposure time. This task was accomplished through integrating the cosmic ray exposure rate along the route while taking into account the changing elevations using the experimentally known exponential relationship between cosmic ray flux and elevation. This relationship was taken to be

$$
\text { Cosmic Ray Exposure Rate }=5^{\text {Elevation (ft)5000ft }}
$$

which has the effect of a fivefold increase in flux every time elevation increases by roughly a mile. The expected routes and the elevation values were both gathered from Google Maps, using the Google Directions application programming interface (API) and Google Elevation API, respectively. Because some of the detector parts were shipped in bulk using FedEx services, the stored tracking information was used to provide more detailed estimates for those transportation records. 


\subsection{Results}

A tool was developed in the Java programming language, which could estimate the exposure time between two arbitrary locations, by predicting the most likely route and sampling altitudes along that route. The results of the calculation for several routes of interest to the Majorana experiment follow in Table 1:

Table 1: Comparison of Actual Travel Time Versus Equivalent Exposure Time

\begin{tabular}{|r|c|c|c|}
\hline & To & $\begin{array}{c}\text { Travel } \\
\text { time(hours) }\end{array}$ & Exposure time (Hours sea level equivalent) \\
\hline Rapid City, SD & PNNL, WA & 16.6 & 99.7 \\
\hline Denver, CO & Rapid City, SD & 6.6 & 32.6 \\
\hline Boise, ID & Denver, CO & 13 & 105.3 \\
\hline Hermiston, OR & Boise, ID & 4.3 & 12.4 \\
\hline Pasco, WA & Hermiston, OR & 0.7 & 1.0 \\
\hline PNNL, WA & Pasco, WA & 0.4 & 0.45 \\
\hline Rapid City, SD & Sanford, SD & 0.95 & 3.3 \\
\hline PNNL, WA & UNC, NC & 44 & 159.2 \\
\hline UNC, NC & LBNL, CA & 45 & 133.0 \\
\hline
\end{tabular}

One result of note was the much higher degree of exposure experienced by materials in the FedEx shipments, compared to those that were driven by car directly from one site to another. Causes for this included the roundabout paths that FedEx trucks took in order to hit as many of their pickup facilities as possible, along with the stops they made to transfer packages to new trucks. One particularly influential stop lasted two days in Denver (altitude: one mile) which greatly contributed to the overall exposure time of that trip.

Using the known properties of ${ }^{60} \mathrm{Co}$, copper, and the cosmic ray flux at sea level, a relation was found between the time of equivalent sea level exposure and the background rate it would produce. This was then compared to the estimates for equivalent exposure of a single transportation, and to the limit for the number of background counts established by the collaboration. 
PNNL-21657

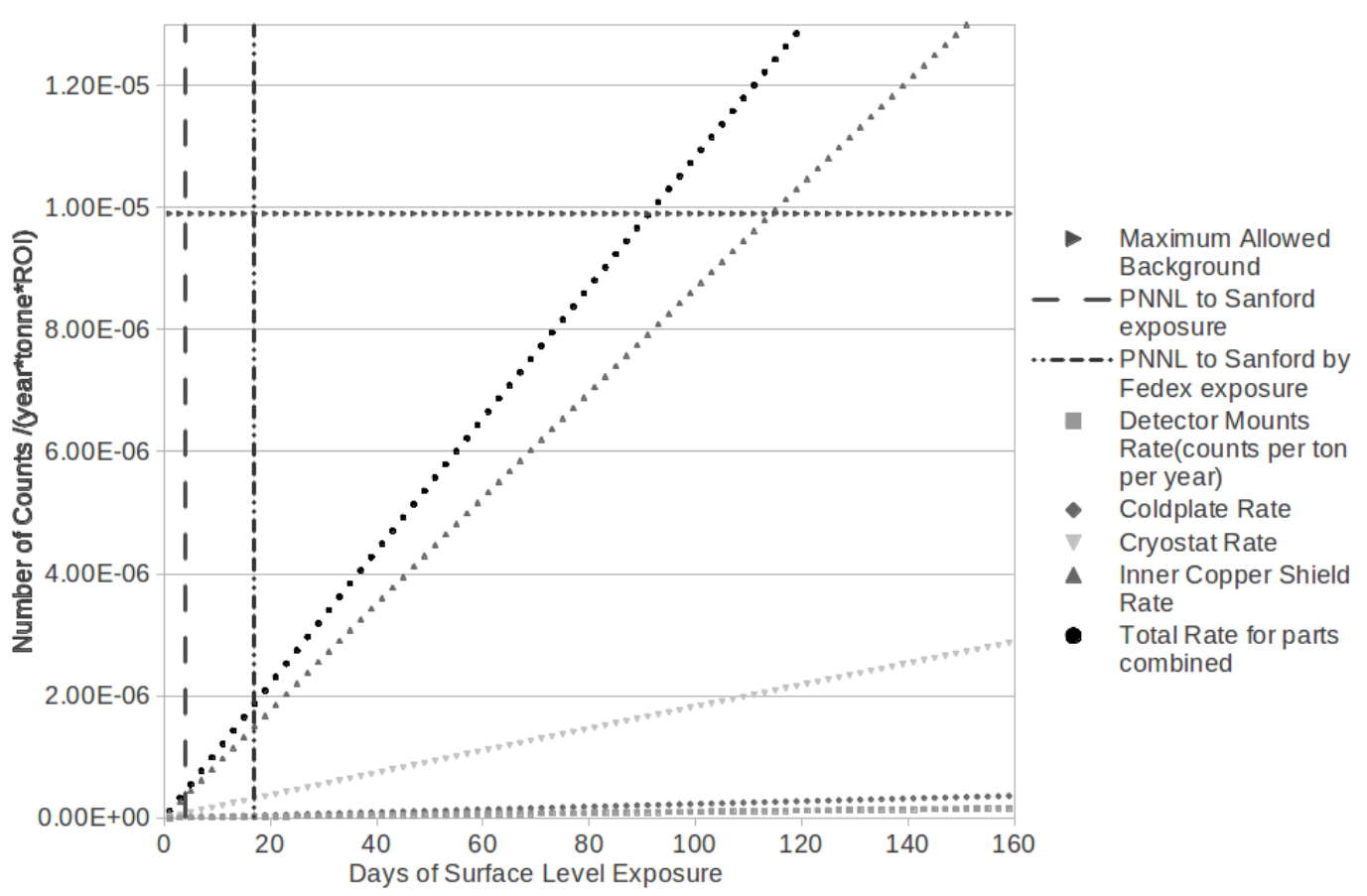

Figure 1: The background rate produced in various copper parts of the detector

It was found that the background contribution for a single trip was negligible, when compared with the maximum allowable limit. However, if a single piece is transported several times and each time received exposure similar to the FedEx shipment, the limit might be surpassed. Considering it is known that several copper pieces will need to be moved between SURF and PNNL several times during the construction phase of the experiment, care should be taken to limit exposure on each of these trips. Taking into account the four factor difference between the FedEx shipment and a direct driving route, the latter is the preferable option. 


\subsection{Conclusions}

More accurate methods for predicting cosmic ray exposure may be found in the future. This analysis did not take into account several known factors that influence cosmic ray flux to a lesser degree, such as latitude and longitude, solar cycle, time of year, and time of day. However, as the largest contributing factor is altitude, these results and the tool developed may provide experimenters with a simple means of judging how to best transport materials to minimize exposure. Furthermore, it will provide a frame of reference to double check the accuracy of future results. 
PNNL-21657

\subsection{References}

Aaselth C, Back H, Dauwe L, Dean D, Drexlin G, Efremenko Y, Ejiri H, Elliott S, Engel J, Fujikawa B, Henning R, Hoffman G.W., Lang K, Lesko K, Kishimoto T, Miley H, Norman R, Pascoli S, Petcov S, Piepke A, Rodejohann W, Saltzberg D, Sutton S, Vogel P, Warner R, Wilkerson J, and Wolfenstein L. Neutrinoless Double Beta Decay and Direct Searches for Neutrino Mass. 2004. arXiv:hep-ph/0412300.

Anderson, Carl D. (1933). "The Positive Electron". Physical Review 43 (6): 491-494.

Apache Software Foundation. "Apache CouchDB". http://couchdb.apache.org/ . Accessed July 2012.

Laubenstein, M and G Huesser. 2009. Cosmogenic radionuclides in metals as indicator for sea level exposure history. Applied Radiation and Isotopes 67, pp 750-754. 


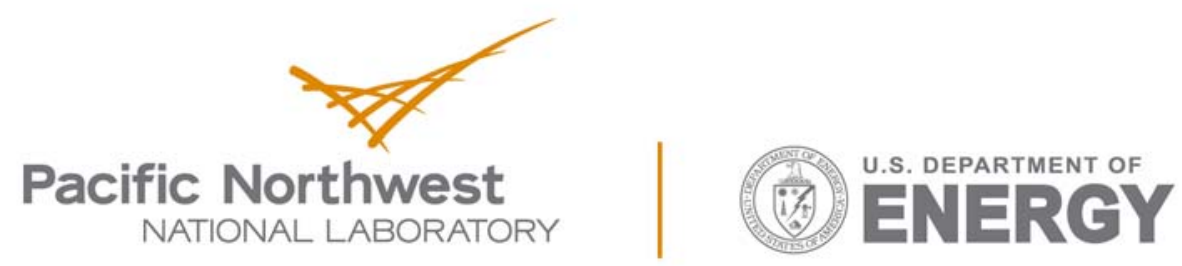

Proudly Operated by Battelle Since 1965

902 Battelle Boulevard

P.O. Box 999

Richland, WA 99352

1-888-375-PNNL (7665)

www.pnnl.gov 